\title{
Effect of Nb Content in the Microstructural and Thermal Characteristics of NiTiNb Shape Memory Alloys
}

\author{
Maria Eurenice Rocha Cronemberger ${ }^{a}$, Vitória Honorato Franco Menezes ${ }^{a}$, Rodrigo da Silva ${ }^{a}$, \\ Ícaro G.R. Santos ${ }^{a}$, Vitor L. Sordi", Sebastião Elias Kuri", Carlos Alberto Della Rovere ${ }^{a *(1)}$ \\ ${ }^{a}$ Universidade Federal de São Carlos (UFSCar), Programa de Pós-Graduação em Ciência e Engenharia \\ de Materiais (PPGCEM), Rod. Washington Luís, $310 \mathrm{~km}$ 235, CEP 13565-905, São Carlos, SP, Brasil
}

Received: January 27, 2019; Revised: September 5, 2019; Accepted: December 5, 2019

\begin{abstract}
The influence of $\mathrm{Nb}$ content variation on the microstructural and thermal characteristics of $\mathrm{NiTiNb}$ alloys was evaluated since these aspects are relevant to the control and adequacy of its shape memory properties for application purposes. The aim of this study was to observe how the $\mathrm{Nb}$ content acts in the formation of $\mathrm{Nb}$-rich precipitates and the eutectic structures, which can make this alloys more complex. Microstructural characterization of the alloys was performed by X-ray diffraction (XRD), scanning electron microscopy (SEM) and microanalysis by energy-dispersive X-ray spectroscopy (EDS), besides the thermal characterization by differential scanning calorimetry (DSC), and the comparison between the $\mathrm{Nb}$ alloys and the NiTi binary alloy. The results demonstrated a proportional dependence between the amount of $\beta-\mathrm{Nb}$ phase in the microstructures and the amount of $\mathrm{Nb}$ dissolved in the NiTi matrix with the $\mathrm{Nb}$ content. Although it was found that the increase in the $\mathrm{Nb}$ content causes the decrease of the martensitic $(\mathrm{Mi})$ and reverse ( $\mathrm{Ai}$ ) transformation temperatures, the magnitude of thermal hysteresis was not significantly changed.
\end{abstract}

Keywords: Shape memory alloy, NiTiNb alloys, niobium, microstructural characterization, SEM/EDS

\section{Introduction}

In practical terms, phase transformation temperature and thermal hysteresis are important parameters to determine the engineering application and performance of shape memory alloys (SMA) ${ }^{1}$. Considering this, it is desirable and perfectly possible to control both the transformation temperature and the thermal hysteresis by thermos-adjusting the chemical composition of the alloy and/or using thermo-mechanical treatment ${ }^{2}$.

In the case of the binary alloy system NiTi, of well-known commercial importance, the addition of a third element ( $\mathrm{Zr}, \mathrm{Hf}, \mathrm{Pd}, \mathrm{V}, \mathrm{Al}$ and $\mathrm{Nb}$ ) has proven to be efficient in controlling and adjusting the transformation temperature, as well as improving its shape memory characteristics and resulting in the widening of the range of the alloy's applications ${ }^{3-7}$. It can also help to control the thermal hysteresis amplitude, increase the austenitic resistance, reduce or increase the martensitic resistance, improve corrosion resistance and suppress the R-phase transformation ${ }^{8}$. Among the possible elements, the choice of niobium ( $\mathrm{Nb}$ ) as a third element is quite attractive, considering that the NiTiNb alloys exhibits large transformation hysteresis and an improvement in the shape memory effects, which is very useful for applications in pipe couplings, for example $e^{1,5,6,9}$.

Although the use of NiTiNb alloys containing $9 \mathrm{at} \% \mathrm{Nb}$ is more representative compared to the others, its preparation is more complex ${ }^{5}$ due to the formation of $\mathrm{Nb}$-rich precipitates.
In that sense, some researches are considering the reduction of the $\mathrm{Nb}$ content in these alloys to evaluate the impact of the eutectic structure in the alloy's properties, ${ }^{4,5,10,11}$. According to them ${ }^{1,5,10,11}$, it seems consensual that the addition of low $\mathrm{Nb}$ contents is not enough to reduce the transformation temperatures and to extend the thermal hysteresis of the alloys. However, regarding the variation of microstructures, according to $\mathrm{Nb}$ content of the alloys, there still have adverse aspects to be evaluated, since it seems not to be fully established. Such as the formation of the eutectic phase, that is simply treated as phase $\beta-\mathrm{Nb}$ in most previous work ${ }^{5,10,12-14}$, while it presents as a microconstituent composed of a lamellar structure of NiTi and $\beta-\mathrm{Nb}$ phases.

In addition, regarding the role of this structure, the $\mathrm{Nb}$ content in solid solution in the matrix and the influence of the ratio between $\mathrm{Ni}$ and $\mathrm{Ti}$ contents in the thermal characteristics should also require clarification. In this sense, as it understands that the subject is not exhausted and that systematic research has not yet been conducted sufficiently, the purpose of this work is to expand the study about the role performed by the $\mathrm{Nb}$ in the microstructural and thermal characteristics of NiTiNb alloys, searching to optimization of the $\mathrm{Nb}$ content in these alloys. Thus, this study focuses on the microstructural and thermal characterization of $\mathrm{NiTiNb}$ alloys with different quantities of $\mathrm{Nb}$ to evaluate how the deviation in the composition of the alloys affects these characteristics, due to its relevance for understanding and improving the shape memory alloys' characteristics. 


\section{Materials and methods}

The study was carried out in NiTiNb alloys that presented three different compositions. In that case, $\mathrm{Nb}$ content varied whilst keeping the proportion between $\mathrm{Ni}$ and $\mathrm{Ti}$ constant at 1.07. The nominal composition of the alloys is indicated below in Table 1.

Ingots of approximately $30 \mathrm{~g}$ were prepared from high purity elements, i.e. Nb pieces Alfa Aesar $99.8 \%$, Ni pieces Alfa Aesar 99.9\% and Ti unalloyed bar, in accordance with ASTM Standard F67, 99.3\%, using the electric arc-melting furnace process with tungsten electrode and water-cooled copper crucible under inert atmosphere (Ar). The calculations for weighing the elements were done to obtain a constant $\mathrm{Ni} / \mathrm{Ti}$ atomic ratio of 1.07 for all the alloys, varying the $\mathrm{Nb}$ content (3, 6 and 9 at\%). An NiTi alloy with the same proportion between the elements was produced and used for comparison.

The alloys were homogenized at $850^{\circ} \mathrm{C}$ for 2 hours and hot rolled at $850^{\circ} \mathrm{C}$ until they reached a width of approximately $5 \mathrm{~mm}$. Solution annealing was performed at $850{ }^{\circ} \mathrm{C}$ for 1 hour, followed by water quenching $5,11,15$.

The samples were cut into cylinders with a diameter of $5 \mathrm{~mm}$ by electric discharge machining (EDM), embedded in cold curing polyester resin, wet sanding with granulometry grades varying from 150 to 600 mesh and polished with 1.0 $\mu \mathrm{m}$ alumina suspension, followed by chemical etching with Kroll's reagent $\left(10 \mathrm{~mL} \mathrm{HF}+30 \mathrm{~mL} \mathrm{HNO}_{3}+50 \mathrm{~mL} \mathrm{H}_{2} \mathrm{O}\right){ }^{16}$.

The microstructural characterization of the alloys was performed using X-ray diffraction (XRD), scanning electrode microscopy (SEM) and energy-dispersive X-ray spectroscopy (EDS). Three regions were selected for each composition of the alloy, and each region's matrix, eutectic phase and $\mathrm{Nb}$-rich precipitates ( $\beta$-Nb particles) was analysed by EDS.

The transformation temperatures of the alloys were verified through DSC tests (differential scanning calorimetry), using samples of approximately $40 \mathrm{mg}$. These samples undergo a thermal cycle between $150{ }^{\circ} \mathrm{C}$ and $-80^{\circ} \mathrm{C}$, with a heating and cooling rate of $10^{\circ} \mathrm{C} / \mathrm{min}$, as specified by the ASTM F2004 ${ }^{17}$.
The martensitic transformation start and final temperatures were measured for each alloy, when possible, and identified as Ms and Mf, respectively. The reverse transformation start and final temperatures (As and Af), as well as the transformation temperature peaks (Mp and $\mathrm{Ap}$, representing the martensitic transformation temperature and the reverse transformation) were measured as well when possible.

\section{Results and Discussion}

The SEM micrographs of the studied alloys, containing 3, 6 and 9 at $\% \mathrm{Nb}$ are presented in Figure $1(\mathrm{~b}-\mathrm{d})$, respectively. The micrograph for the NiTi alloy is presented in Figure 1 (a), for comparison.

Note that, unlike the NiTi alloy, the NiTiNb alloys show a distinguishable dendritic microstructure. This represents a typical hypoeutectic microstructure, which is mainly composed of a NiTi $(\alpha)$ matrix, identified in the micrographs as a dark grey region, surrounded by an interdendritic eutectic structure $(\alpha+\beta-\mathrm{Nb})$, identified as a light grey region in the grain boundaries, whose formation result of an eutectic reaction, according to the pseudobinary diagrams presented by Piao et al. ${ }^{18}$ and Shi et al. ${ }^{3}$ illustrated in Figure 2.

Figure $1(b-d)$ also shows an increase of the eutetic structure's volumetric fraction with the increase of the $\mathrm{Nb}$ content in the alloys, showing that $\mathrm{Nb}$ cannot be completely dissolved in the NiTi matrix as predicted by the pseudo-binary diagram, which results in an eutectic phase, as observed by Ying et al. ${ }^{11}$.

The EDS results shown on Table 2, present the average of the analysis results in the selected points (1: matrix; 2 : eutectic phase; 3: $\beta$-Nb particles), as presented in Figure 3 (a), (b) and (c ). The matrix NiTi (1) presents a certain $\mathrm{Nb}$ amount dissolved, which increases as a function of $\mathrm{Nb}$ addition in the alloys. The eutectic structure (2) also becomes more enriched in $\mathrm{Nb}$, that is, the amount of $\mathrm{Nb}$ contained in this structure also increases with the increase of the content of this element in the alloy, as it was noticed by Jiang et al. and Xiao Fu et al. ${ }^{1,19}$.

Table 1. Nominal composition of the alloys (\% atomic).

\begin{tabular}{ccccc}
\hline Material & Ni/Ti & Ni & Ti & Nb \\
\hline NiTi & 1 & 50 & 50 & - \\
NiTi3Nb & 1.07 & 50 & 47 & 3 \\
NiTi6Nb & 1.07 & 49 & 45 & 6 \\
NiTi9Nb & 1.07 & 47 & 44 & 9 \\
\hline
\end{tabular}

Table 2. EDS results (\% atomic).

\begin{tabular}{|c|c|c|c|c|c|c|c|c|c|}
\hline \multirow[t]{2}{*}{ Material } & \multicolumn{3}{|c|}{ Spot 1} & \multicolumn{3}{|c|}{ Spot 2} & \multicolumn{3}{|c|}{ Spot 3} \\
\hline & $\mathbf{N i}$ & $\mathbf{T i}$ & $\mathbf{N b}$ & $\mathrm{Ni}$ & $\mathbf{T i}$ & $\mathbf{N b}$ & $\mathrm{Ni}$ & $\mathbf{T i}$ & $\mathbf{N b}$ \\
\hline $\mathrm{NiTi} 3 \mathrm{Nb}$ & 51.23 & 46.80 & 1.97 & 49.86 & 44.32 & 5.82 & - & - & - \\
\hline $\mathrm{NiTi6Nb}$ & 50.32 & 46.06 & 3.62 & 42.99 & 41.02 & 15.99 & 33.61 & 36.34 & 30.05 \\
\hline NiTi9Nb & 49.86 & 45.27 & 4.87 & 40.37 & 38.13 & 21.50 & 31.03 & 34.54 & 34.43 \\
\hline
\end{tabular}



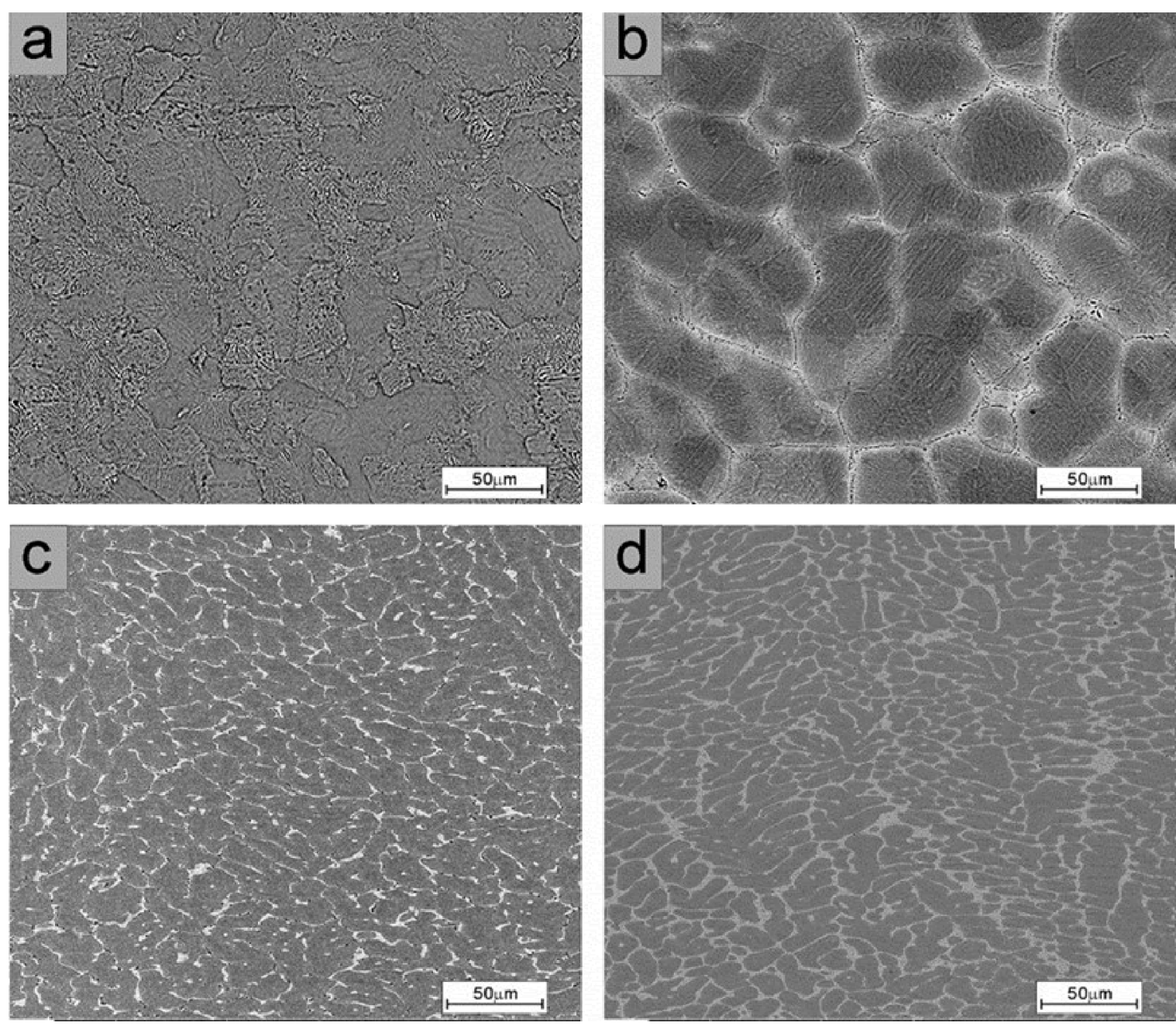

Figure 1. SEM micrographs of the solution annealing treated alloys (a) NiTi, (b) NiTi3Nb, (c) NiTi6Nb and (d) NiTi9Nb.

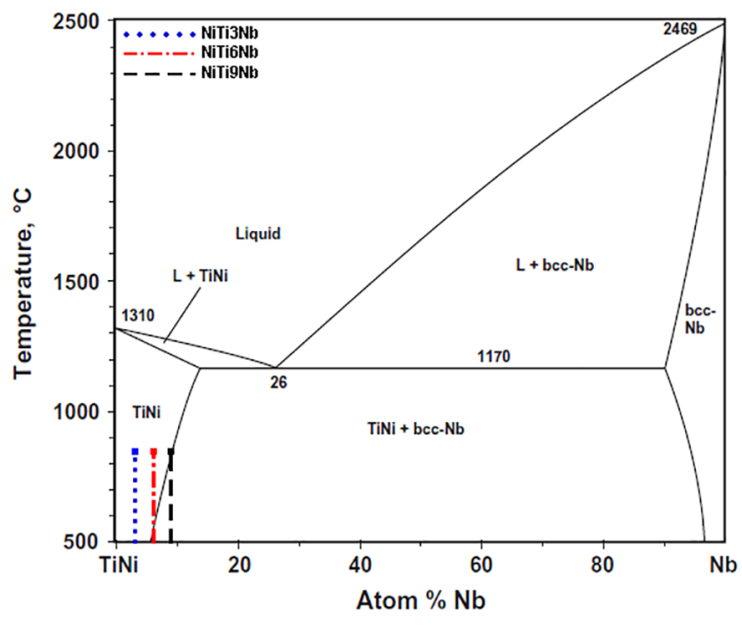

Figure 2. Phase diagram of the pseudo-binary "NiTi-Nb" system with studied compositions highlighted ${ }^{3}$.
Analogously, Zhang et al., He et al. and Zhao et al. have reported fairly consistent EDS results in alloys with nominal composition $47 \mathrm{Ni}-44 \mathrm{Ti}-9 \mathrm{Nb}$ (at\%), demonstrating that there is a mutual solubility of both the $\mathrm{Nb}$ in the NiTi matrix and of both $\mathrm{Ni}$ and $\mathrm{Ti}$ in the $\beta-\mathrm{Nb}$ phase ${ }^{5,10,20}$. EDS analyses in point 3 show that the lighter regions of the eutectic phase can be identified as $\beta-\mathrm{Nb}$ particles ( $\mathrm{Nb}$ enriched particles).

Besides the main phases already mentioned, some dark particles (represented in black) were found and identified as compounds containing $\mathrm{Ti}, \mathrm{Ni}$ and $\mathrm{Nb}$, similar to the ones pointed out as oxide particles $(\mathrm{TiNb})_{4} \mathrm{Ni}_{2} \mathrm{O}$ by Xiao Fu et al. ${ }^{19}$, Zhao et al. ${ }^{10}$ and Wei and Xinqing ${ }^{12}$.

The XRD spectra obtained for the different compositions are shown in Figure 4. Besides presenting a primary phase, NiTi austenitic (B2) and martensitic (B19'), the binary alloy NiTi also shows two secondary phases, including $\mathrm{Ni}_{4} \mathrm{Ti}_{3}$ rich in $\mathrm{Ni}$ and $\mathrm{Ti}_{2} \mathrm{Ni}$ rich in $\mathrm{Ti}$, as observed by $\mathrm{Chu}$ et al. ${ }^{21}$. 
The peaks of these phases are suppressed with the $\mathrm{Nb}$ addition. As a result, only the phase $\mathrm{Ti}_{2} \mathrm{Ni}$ can be observed with low intensity in the samples containing 3 at. $\% \mathrm{Nb}^{13}$. The samples of the alloys containing 6 at. $\% \mathrm{Nb}$ and 9 at. $\% \mathrm{Nb}$ do not present peaks corresponding to secondary phases. In these cases, besides the NiTi (B2 and B19') matrix, the $\beta-\mathrm{Nb}$ phase can be observed ${ }^{1,13,18,22}$

On the contrary, the results for the alloy with 3 at. $\% \mathrm{Nb}$ do not show a crystalline peak for the $\beta-\mathrm{Nb}$ phase, suggesting that the $\beta-\mathrm{Nb}$ particles in the eutectic phase $(\alpha+\beta-\mathrm{Nb})$, finely distributed in small quantities, cannot be detected. The reason for that is possibly due to its small volume when compared to the matrix volume, or due to it being covered by the noise resulting from the analysis. By means of XRD analysis, He et al. ${ }^{5}$ have observed only low intensity peaks for alloys with similar composition and they did not observe $\beta-\mathrm{Nb}$ particles through SEM analysis. Finally, the presence of carbides, oxides or free $\mathrm{Ti}$ and $\mathrm{Ni}$ was not detected, just as the analysis presented by $\mathrm{Li}$ et al. ${ }^{13}$. This suggests that the dark particles (shown in black), identified as possible oxide particles (like previously mentioned) are probably present in a very small volumetric fraction.

Figure 5 shows the resulting curves from the DSC analysis, making possible to observe the behaviour of the samples during thermally induced transformation. The exothermic peak on cooling represents the transformation from austenite phase to martensite phase, and the endothermic peak on heating is related to the reverse transformation from martensite to austenite phase. The transformation temperatures (Ms, Mf, As and Af) were determined from the intersections of two tangential lines to the cooling and heating peaks through the inflection points ${ }^{17}$ and are shown on Table 3.

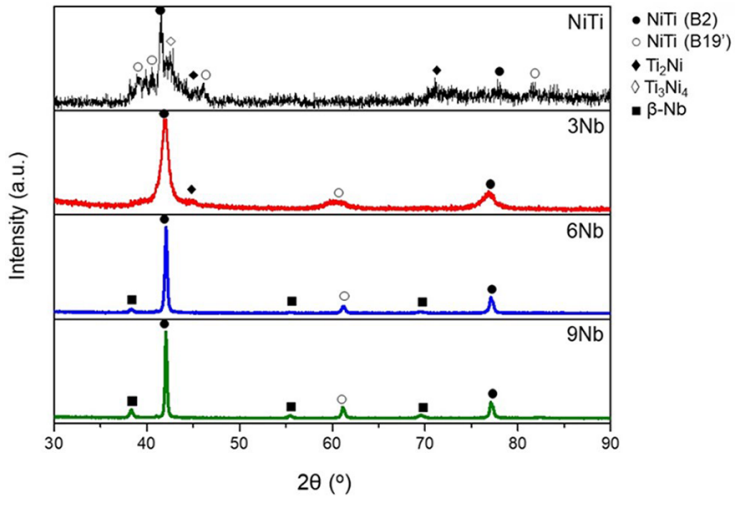

Figure 4. XRD spectra of the alloys NiTi and NiTiNb with different amounts of $\mathrm{Nb}$.

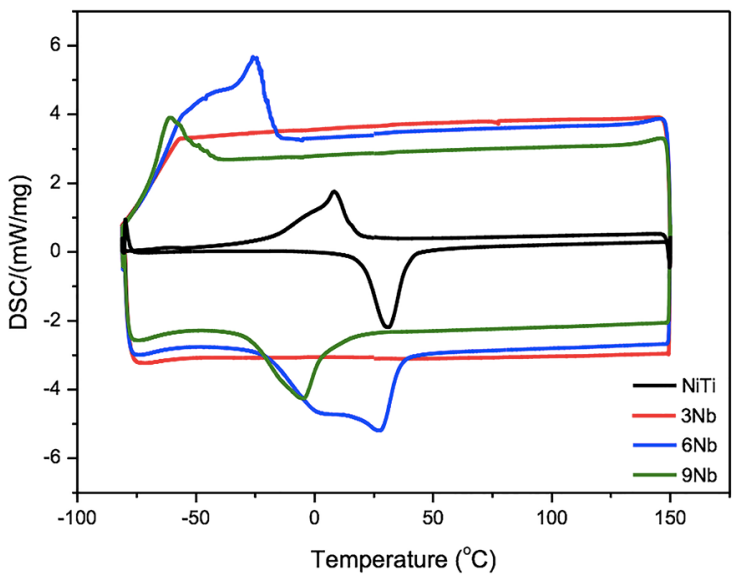

Figure 5. Resulting curves from the DSC analysis for the NiTi and $\mathrm{NiTiNb}$ alloys with different $\mathrm{Nb}$ contents.
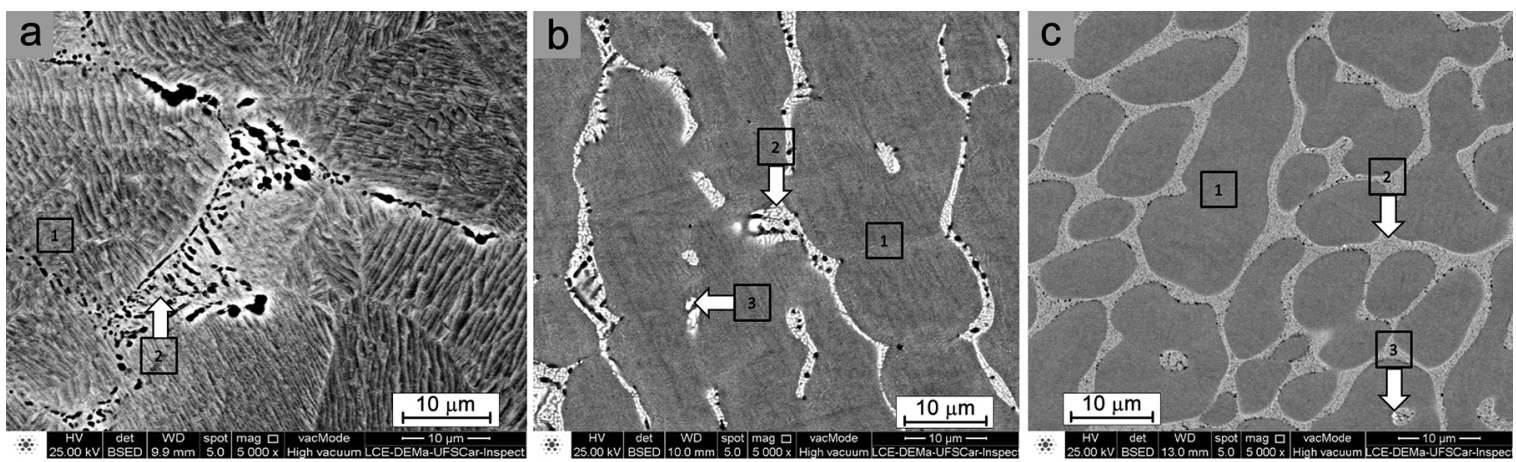

Figure 3. SEM micrographs of the alloys (a) NiTi3Nb, (b) NiTi6Nb and (c) NiTi9Nb, indicating the points chosen for the EDS analyses: (1) matrix, (2) eutectic phase, (3) $\beta$-Nb particles.

Table 3. Transformation temperatures $\left({ }^{\circ} \mathrm{C}\right)$ obtained by the DSC curves.

\begin{tabular}{ccccccccc}
\hline Material & Ms & Mf & Mp & As & Af & Ap & (As-Ms) & (Ap-Mp) \\
\hline NiTi & 5 & -16 & 8 & 20 & 39 & 31 & 15 & 23 \\
NiTi3Nb & n.d. & n.d. & n.d. & n.d. & n.d. & n.d. & n.d. & n.d. \\
NiTi6Nb & -16 & -33 & -25 & 17 & 37 & 28 & 33 & 53 \\
NiTi9Nb & -53 & -70 & -61 & -28 & 2 & -5 & 25 & 56 \\
\hline
\end{tabular}

n.d.: not determined 
This could not be done for the alloy with 3 at. $\% \mathrm{Nb}$ since the curve for its thermal behaviour shows no exothermic or endothermic peaks, meaning that there are no variations in the heat flow that would allow the identification of the characteristic transformation temperature.

The NiTi and NiTi9Nb alloys exhibit one-step phase transformation (B2 $\rightarrow$ B19'), in which the exothermic peak on cooling represents the transformation from the austenite, B2, to the martensite, B19', and the endothermic peak on heating is related to the inverse transformation from martensite, B19', to austenite, B2, as observed by He et al. ${ }^{5}$, Ying et al. ${ }^{11}$, Fu et al. ${ }^{19}$. According to Tong et al. ${ }^{14}$, the absence of an intermediate phase transformation (R-phase) in ternary alloys can be related to de significant quantity of $\mathrm{Nb}$ in solid solution in the matrix, increasing the energetic barrier for the intermediate phase transformation.

However, in the curve for the alloy with 6 at.\% $\mathrm{Nb}$, two peaks can be seen both for the cooling and the heating processes, which suggests that this alloy exhibits a two-step transformation (B2 $\rightarrow \mathrm{R} \rightarrow \mathrm{B} 19^{\prime}$ ). The first peak, in cooling, represents a transformation from $\mathrm{B} 2$ to $\mathrm{R}$ and the second peak, in the lower temperature, indicates a transformation from $\mathrm{R}$ to $\mathrm{B} 19^{\prime 23}$.

According to literature ${ }^{24-26}$, there are many reasons possibly leading to R-phase transformations in NiTi alloys, both related to the composition, as well as to mechanical and/or thermal treatments of these alloys. Zheng et al. ${ }^{26}$, for example, mention the lack of homogeneity in the matrix as being responsible for the R-phase transformation. It is also possible to suggest that the $\mathrm{Nb}$ content dissolved in the matrix, which is lower than the amount found in the sample with 9 at.\% $\mathrm{Nb}$, is not significant enough to raise the energy barrier for the R-phase transformation. In this case, however, more investigations are necessary to clarify this hypothesis.

The martensitic transformation for the alloy with 6 at. $\% \mathrm{Nb}$ initiates $(\mathrm{Ms})$ in $-16{ }^{\circ} \mathrm{C}$, while in the alloy with 9 at. $\% \mathrm{Nb}$ the starting temperature for the martensitic transformation is $-53{ }^{\circ} \mathrm{C}$, being both values considerably lower than the ones obtained for the NiTi alloy $\left(5^{\circ} \mathrm{C}\right)$. Similar results were obtained by $\mathrm{Fu}$ et $\mathrm{al}^{19}$ and Jiang et al. ${ }^{1}$, who reported that the higher the $\mathrm{Nb}$ content, the lower the martensitic transformation temperatures. According to Shi et al. ${ }^{3}$, the lowering of the starting temperature for the martensitic transformation is partially due to the fact that $\mathrm{Nb}$ atoms usually substitute the $\mathrm{Ti}$ atoms, changing the $\mathrm{Ni} / \mathrm{Ti}$ ratio in the matrix and resulting in the lowering of the Ms, which confirms the EDS results presented in Table 3.

Thermally induced transformation hysteresis (As - Ms) result in approximated values for the samples with 6 and 9 at. $\% \mathrm{Nb}$, at $33{ }^{\circ} \mathrm{C}$ and $25^{\circ} \mathrm{C}$, respectively.
These values are higher than the thermal hysteresis for the binary alloy at $15^{\circ} \mathrm{C}$, but it is possible to conclude that there is no substantial increase in the hysteresis when $\mathrm{Nb}$ is added to the alloy. Jiang et al. ${ }^{1}$ showed that, in order to increase the hysteresis of the NiTi alloy's transformation, it is necessary not only to reduce the starting temperature for the martensitic transformation, but to increase the temperature for the reverse transformation (As) simultaneously. This does not happen with the studied alloys, which presented a decrease in temperature for the reverse transformation as well, with a temperature of $17^{\circ} \mathrm{C}$ for the alloy with 6 at.\% $\mathrm{Nb}$, a value close to the ones observed for the binary alloy's As $\left(20{ }^{\circ} \mathrm{C}\right)$. For the alloy with 9 at. $\% \mathrm{Nb}$ the temperature observed was $-28^{\circ} \mathrm{C}$.

According to Lin et al. ${ }^{2}$, although the temperature for the martensitic transformation is strongly dependent of the chemical composition, the thermal hysteresis control can also be the result of the combination of a change in this composition and the application of thermomechanical treatments, such as thermal cycling, aging in alloys with high Ni content, and hardening followed or not by annealing. Zhao et al. ${ }^{27}$ proposed that the plastic deformation of the $\mathrm{Nb}$ particles plays an important role in the increase of the NiTiNb alloy's transformation hysteresis, even for small deformations. The authors suggest that the presence of these particles decomposes the deformation of the martensitic structure in a reversible component (the NiTi matrix) and in an irreversible component (phase containing $\mathrm{Nb}$ ), which makes the martensite reverse transformation difficult by maintaining the deformation of $\beta$-Nb particles. Additionally, Wei and Xinqing (2009) and Wang et al. (2012) noted that the $\mathrm{Nb}$ in solid solution can change the martensitic and reverse transformation kinetics under a proper pre-deformation, providing an elastic strain energy storage and martensite stabilization. Moreover, about the reverse transformation temperature, Jiang et al. (2016) explained its variation in terms of the variation of Gibbs free energy, which is composed of combination of the chemical free energy and elastic strain energy for transformation from martensite to austenite. According to the authors, when a great deal of elastic strain energy is stored in the martensite during martensitic transformation, the elastic strain energy contributes to increasing the driving force for the reverse transformation from martensite to austenite in the case of heating, which leads to the decrease in the austenitic transformation start temperature As. Thus, the solution annealing treatment after hot rolling of the studied alloys may have led to the plastic deformation energy relaxation of $\beta-\mathrm{Nb}$ particles stored at the interface of the martensite, avoiding the increase of the reverse transformation start temperature.

The comparative of the transformation temperatures' variation is shown in Figure 6, in which is possible to observe how the thermal behaviour of the alloys follows a similar pattern as a function of the $\mathrm{Nb}$ addition. 


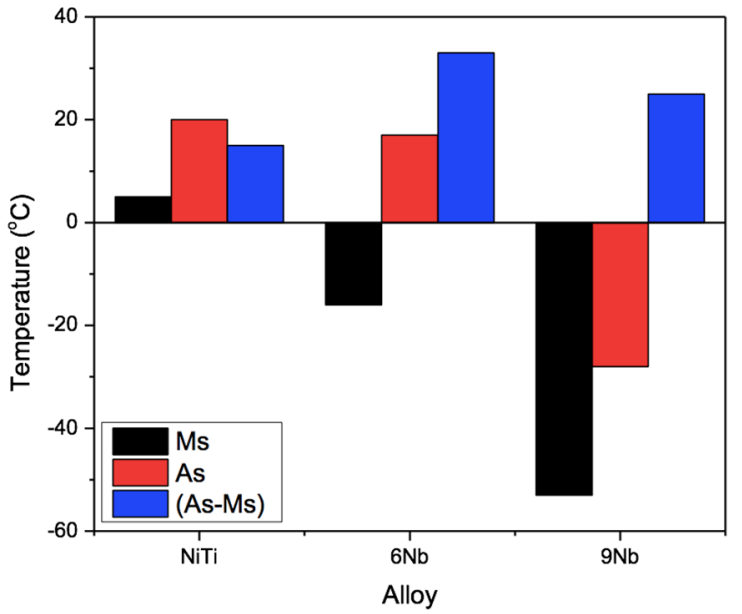

Figure 6. Martensitic transformation start temperature (Ms), Reverse transformation start temperature (As) and thermically induced transformation hysteresis (As-Ms) variations of NiTi, NiTi6Nb and $\mathrm{NiTi9} \mathrm{Nb}$ alloys samples.

It can also be noted that as $\mathrm{Nb}$ content increases in the alloy, the martensitic transformation start temperature (Ms) and the reverse transformation start temperature (As) decrease, while the thermally induced transformation hysteresis (As - Ms) increases, although not significantly, as discussed above.

\section{Conclusion}

The influence of $\mathrm{Nb}$ addition in the microstructural and thermal characteristics of the three NiTiNb alloys Ni50Ti47Nb3, Ni49Ti45Nb6 and Ni47Ti44Nb9 (at.\%) - in comparison with a NiTi equiatomic alloy was investigated. The main conclusions are as follows.

The NiTiNb alloys show characteristic hypoetectic microstructure composed by a NiTi matrix involved by a eutectic structure, in which volumetric fraction increases with the increase of $\mathrm{Nb}$ content in the alloys.

Both the primary NiTi phase and the eutectic phase are $\mathrm{Nb}$-enriched with the increase of $\mathrm{Nb}$ content in the alloys.

$\mathrm{The} \mathrm{Nb}$ addition in the binary NiTi alloy and the increase of $\mathrm{Nb}$ content in the ternary alloys result in a decrease of the martensitic transformation start temperature, Ms, as well as the reverse transformation start temperature, As. However, the magnitude of the thermal transformation hysteresis of the ternary alloys has not been significantly changed with the $\mathrm{Nb}$ content.

\section{Acknowledgements}

This study was financed in part by the Coordenação de Aperfeiçoamento de Pessoal de Nível Superior - Brasil (CAPES) - Finance Code 001 (inglês). Additionally, the authors would like to thank the PPGCEM/ UFSCar (Postgraduate Program in Materials Science and Engineering at the
Federal University of São Carlos) and the Brazilian research funding agency CNPq (National Council for Scientific and Technological Development - Grant number 311163/2017-3) for the financial support of this study. SEM/EDS and XRD facilities were provided by Structural Characterization Laboratory of the Materials Engineering Department of the Federal University of São Carlos - LCE/ DEMa/UFSCar.

\section{References}

1. Jiang S, Liang Y, Zhang Y, Zhao Y, Zhao C. Influence of addition of $\mathrm{Nb}$ on phase transformation, microstructure and mechanical properties of equiatomic NiTi SMA. Journal of Materials Engineering and Performance. 2016;25(10):4341-51.

2. Lin HC, Wu SK, Chou TS, Kao HP. The effects of cold rolling on the martensitic transformation of an equiatomic TiNi alloy. Acta Metallurgical et Materialia. 1991;39(9):2069-80.

3. Shi H, Frenzel J, Martinez GT, Van Rompaey S, Bakulin A, Kulkova $\mathrm{S}$, et al. Site occupation of $\mathrm{Nb}$ atoms in ternary $\mathrm{Ni}$ Ti-Nb shape memory alloys. Acta Materialia. 2014.

4. Cai W, Meng XL, Zhao LC. Recent development of TiNibased shape memory alloys. Current Opinion in Solid State and Materials Science. 2004;9(6):296-302.

5. He XM, Rong LJ, Yan DS, Li YY. TiNiNb wide hysteresis shape memory alloy with low niobium content. Materials Science and Engineering: A. 2004;371(1-2):193-7.

6. Piao M, Miyazaki S, Otsuka K. Characteristics of deformation and transformation in Ti44Ni47Nb9 shape memory alloy. Materials Transactions. 1992;33(4):346-53.

7. Otsuka K, Ren X. Physical metallurgy of Ti-Ni-based shape memory alloys. Progress in Materials Science. 2005;50:511-678.

8. Duerig TW, Melton KN, Stockel D, Wayman CM. Engineering aspects of shape memory alloys. Oxford: Butterworth-Heinemann; 1990

9. Shi H, Pourbabak S, Van Humbeeck J, Schryvers D. Electron microscopy study of $\mathrm{Nb}$-rich nanoprecipitates in $\mathrm{Ni}-\mathrm{Ti}-\mathrm{Nb}$ and their influence on the martensitic transformation. Scripta Materialia. 2012;67(12):939-42.

10. Zhao X, Yan X, Yang Y, Xu H. Wide hysteresis NiTi(Nb) shape memory alloys with low $\mathrm{Nb}$ content (4.5 at.\%). Materials Science and Engineering: A. 2006;438-440:575-8.

11. Ying C, Hai-Chang J, Li-Jian R, Li X, Xin-Qing Z. Mechanical behavior in NiTiNb shape memory alloys with low $\mathrm{Nb}$ content. Intermetallics. 2011;19(2):217-20.

12. Wei L, Xinqing Z. Mechanical properties and transformation behavior of NiTiNb shape memory alloys. Chinese Journal of Aeronautics. 2009;22(5):540-3.

13. Li J, Wang H, Liu J, Ruan J. Effects of $\mathrm{Nb}$ addition on microstructure and mechanical properties of TiNiNb alloys fabricated by elemental powder sintering. Materials Science and Engineering: A. 2014;609:235-40.

14. Tong YX, Jiang PC, Chen F, Tian B, Li L, Zheng YF, et al. Microstructure and martensitic transformation of an ultrafinegrained $\mathrm{TiNiNb}$ shape memory alloy processed by equal channel angular pressing. Intermetallics. 2014;49:81-6. 
15. Tosetti JP, Silva GA, Otubo J. Microstructure evolution during fabrication of Ni-Ti-Nb SMA Wires. Materials Science Forum. 2014;775-776:534-37.

16. American Society For Testing And Materials (ASTM). E407:07 - Standard practice for microetching metals and alloys. West Conshohocken, PA: ASTM International; 2015.

17. American Society For Testing And Materials (ASTM). F2004 - Standard test method for transformation temperature of nickeltitanium alloys by thermal analysis. West Conshohocken, PA: ASTM International; 2017.

18. Piao M, Miyazaki S, Otsuka K, Nishida N. Effects of Nb addition on the microstructure of Ti-Ni alloys. Materials Transactions. 1992;33(4):337-45.

19. Fu X, Guojun M, Xinqing Z, Huibin X. Effects of Nb content on yield strength of nitinb alloys in martensite state. Chinese Journal of Aeronautics. 2009;22(6):658-62.

20. Zhang CS, Wang YQ, Chai W, Zhao LC. The study of constitutional phases in a Ni47Ti44Nb9 shape memory alloy. Materials Chemistry and Physics. 1991;28(1):43-50.

21. Chu CL, Chung JC, Chu PK. Effects of heat treatment on characteristics of porous Ni-rich NiTi SMA prepared by SHS technique. Transactions of Nonferrous Metals Society of China. 2006;16(1):49-53.
22. Yin XQ, Mi X, Li Y, Gao B. Microstructure and properties of deformation processed polycrystalline $\mathrm{Ni}_{47} \mathrm{Ti}_{44} \mathrm{Nb}_{9}$ shape memory alloy. Journal of Materials Engineering and Performance. 2012;21(12):2684-90.

23. Chen Y, Jiang HC, Liu SW, Rong LJ, Zhao XQ. The effect of Mo additions to high damping Ti-Ni-Nb shape memory alloys. Materials Science and Engineering: A. 2009;512(1-2):26-31.

24. Kim JI, Liu Y, Miyazaki S. Ageing-induced two-stage R-phase transformation in Ti - 50.9at.\%Ni. Acta Materialia. 2004;52(2):487-99.

25. Wang L, Wang C, Zhang LC, Chen L, Lu W, Zhang D. Phase transformation and deformation behavior of NiTi-Nb eutectic joined NiTi wires. Scientific Reports. 2015;6:23905.

26. Zheng HX, Mentz J, Bram M, Buchkremer HP, Stöver D. Powder metallurgical production of $\mathrm{TiNiNb}$ and $\mathrm{TiNiCu}$ shape memory alloys by combination of pre-alloyed and elemental powders. Journal of Alloys and Compounds. 2008;463(1-2):250-6.

27. Zhao LC, Duerig TW, Justi S, Melton KN, Proft JL, Yu W, et al. The study of niobium-rich precipitates in a Ni-Ti-Nb shape memory alloy. Scripta Metallurgica et Materialia. 1990;24(2):221-5. 